\title{
Centralidade ontológica do trabalho ou centralidade da informação e do conhecimento nos processos de formação humana?
}

Hormindo Pereira de Souza Júnior *

Resumo: Este artigo procura realizar uma discussão com algumas das mais importantes e atuais concepçôes teóricas acerca da problemática que envolve a questão da centralidade do trabalho na formação humana. Procuramos contextualizar as recentes transformaçóes ocorridas na base material da produção social no interior da ordem do capital e suas consequiências para os diversos aspectos que envolvem desde a produção e reprodução social dos conhecimentos até os processos de formação dos sujeitos.

Palavras-chave: trabalho; informação; conhecimento; ontologia social.

\section{Ontological centrality of work or centrality of information and knowledge} in the processes of human formation?

Abstract: This article is an attempt to hold a discussion about some of the most important and current theoretical conceptions regarding the problem that involves the question of the centrality of work in human formation. We have tried to contextualize recent transformations that have taken place on the material basis of social production in the interior of the capital order and their consequences for the various aspects that they involve, from the social production and reproduction of knowledge to the formation processes of the subjects.

Key words: work; information; knowledge; social ontology.

Um dos traços fundamentais do mundo do capital, no final do século XX e início do século XXI, é que aquele ampliou de forma substancial seu caráter global, ao passar por um conjunto de conformaçôes arquitetônicas que visam a atualizar seus pressupostos de reprodução, mantendo todo o seu acervo fundamental. A nova divisão internacional do trabalho e da produção desenvolveu novas formas de organização e de gerenciamento dos processos de trabalho.

Amplamente favorecidas pelo desenvolvimento da microeletrônica, da informática, da biotecnologia, da engenharia genética, da inteligência artifici-

Professor Doutor do Departamento de Administração Escolar da Faculdade de Educação da Universidade Federal de Minas Gerais (UFMG).Brasil. hormindojunior@gmail.com 
al, pelo laser, pelos novos materiais sintéticos, pelos sistemas integrados, pelas telecomunicaçóes, as "metamorfoses" pelas quais passa o sistema do capital produzem mudanças em todas as esferas da vida social. A mundializaçăo, considerada como novo processo civilizatório, imprime um novo quadro social e mental de referência e significados, que abre novos horizontes para indivíduos, grupos e classes sociais. Modificam-se estilos de pensamento e de opinião. O nacional, o provinciano, o local, compreendendo identidades e diversidades, desigualdades e antagonismos, adquirem novos significados.

Ou seja, esta é, sem dúvida, uma nova fase de acumulação, caracterizada pela versatilidade da produção e da utilização da força de trabalho.

A centralização do capital, aliada à descentralização das operações produtivas, comerciais e financeiras, reorganiza a economia e a geopolítica do mundo. Nesse contexto, os grupos industriais multinacionais ganham força, introduzindo novas formas de gestão e de controle do trabalho, da produção e dos mercados. Chesnais (1996) utiliza a noção de oligopólio mundial para tratar a forma pela qual as grandes empresas se organizam ao redor do mundo a partir de um espaço de "rivalidade industrial" - espaço definido pela concorrência, mas também pela colaboração entre os grupos. É este o espaço da ocorrência de relações diversificadas, que articulam o investimento externo direto - IED aos grandes grupos multinacionais. O investimento estrangeiro na economia mundial não é um fato novo.

Os marcantes fatos históricos do final da década de 1980, particularmente em 1989, com a queda do muro de Berlim e, posteriormente, o colapso ou a derrocada do pretenso "socialismo real", geraram, de um lado, o ufanismo apologético de uma ordem mundial "unipolar", ressuscitando as teorias conservadoras ou neoconservadoras (neoliberais) e mascarando a mais profunda crise do capitalismo no final do século XX; de outro, decretaram o fim da possibilidade de uma alternativa ao capitalismo e das teorias que sustentam essa alternativa. Postula-se, dentro desta significação, o "fim da história", "fim das ideologias", "das utopias", "das classes sociais", consequientemente do proletariado, e a emergência da "sociedade pós-industrial", "da sociedade da informação" ou a "sociedade do conhecimento", onde o trabalho já não seria o centro. O atual momento histórico sobre o qual nos movemos, ao contrário da aparente evidência e clareza, é opaco, reificado e fetichizado. Novos personagens e "novas máscaras" movem-se nas relaçôes sociais capitalistas, de sorte que a violência do capital e das relaçóes de classe obscurecem, cada vez mais, seu fundamento. A idéia de revolução tecnológica e os conceitos de sociedade do conhecimento, sociedade da informação (não mais sociedade de classe), formação de competências, formação polivalente e flexível, qualidade total e empregabilidade, em planos diversos, prestam-se para ampliar a fetichização e 
os processos de crescente mercantilização e mercadorização da educação, constituindo-se em novas formas de exploração da força de trabalho.

Boa parte da literatura mostra os limites intrínsecos da possibilidade de o capital generalizar o desenvolvimento social, econômico, cultural e o produto do trabalho social. O elemento histórico-empírico desse limite parece ter ficado mais claro no final do século XX.

Istvan Mészáros, em sua obra de maior relevância - Beyond capital (1995) salienta que a forma capital de relaçôes sociais evidenciou, no fim do século, ter esgotado sua capacidade civilizatória e somente pode manter-se mediante maior ímpeto de destruição. Para ele, "já há algum tempo o capitalismo perdeu a sua função civilizatória como organizador impiedoso, mas eficiente do trabalho". Nesta obra, o autor afirma que o sistema do capital se funda cada vez mais no desperdício, na "obsolescência planejada", na produção de armas e no desenvolvimento do complexo militar. É visível que esse impulso incontrolável para a expansão já produziu destruição dos recursos naturais e do meio ambiente. Esse sistema, na visão de Mészáros, produz intensamente trabalho supérfluo. Sem contar que nos últimos 20 anos o capitalismo vem abolindo todas as concessōes do chamado Estado de bem-estar social que justificava sua existência.

A dimensão mais crucial dos limites do capital e do desenvolvimento capitalista, no final do século passado e no início deste, é dada pela intensa destruição de postos de trabalho - síndrome do desemprego estrutural -, pela precarização (flexibilização) do trabalho, vinculada com a abolição dos direitos sociais duramente conquistados pelos trabalhadores. Esse processo dá-se pela conjugação da mundialização excludente, que amplia o desenvolvimento desigual, e pelo monopólio privado da ciência e da tecnologia.

Vinculada ao monopólio crescente da base científica e tecnológica, a mundialização permite um verdadeiro movimento de autovalorização do capital pela intensa exploração da força de trabalho. De um lado, a nova base tecnológica, marcadamente flexível, permite um rápido deslocamento de investimentos produtivos de uma parte para outra do mundo (desterritorialização do capital) para buscar vantagens nas taxas de lucro e, de outro lado, aumenta exponencialmente a intensidade do capital morto e conseqüentemente diminui o capital vivo. E está aqui a especificidade da "mundialização do capital”, na visão de Chesnais. Vale ressaltar que é com estas armas que o capital vem desmobilizando e minguando a organização e o poder sindical, que se vê forçado a negociar direitos conquistados por uma garantia mínima do emprego. Amplia-se, nesse contexto, a possibilidade de superexploração da força de trabalho.

Este momento atual do sistema do capital reordena sua base e sua superestrutura, sem que, com isso se modifique a sua essência visivelmente autofágica, que produz riquezas ao mesmo tempo que desproduz o homem. A busca de 
maximização de lucros, pela redução cada vez maior do valor da força de trabalho, obedece à lógica intrínseca ao modo de produção capitalista. Neste intento, o sistema destrói suas próprias bases, num movimento de autodestruição de si mesmo. Essa lógica gera, em escala planetária, uma grande massa de proletários e ociosos compulsórios cada vez mais pobres e famintos. É a destruição do próprio homem em suas bases humano-societárias. Como nos informa Mészáros (1989, p.102):

[...] o capital é totalmente desprovido de medida e de um quadro de orientação humanamente significativos, enquanto que seu impulso interior pela auto-expansão éa priori incompatível com os conceitos de controle e limite, e desde logo com o de uma autotranscendência positiva. É por isto que corresponde à linha de menor resistência do capital levar as práticas materiais da destrutiva auto-reprodução ampliada ao ponto em que fazem surgir o espectro da destruição global, em lugar de aceitar as requeridas restriçóes positivas no interesse da produção para a satisfação das necessidades humanas.

Esse novo padrão de acumulação exige a reestruturação profunda das bases em que se assenta a acumulação do capital, as quais vêm implicando a adoção de medidas que por sua vez trazem grandes transformaçôes à sociedade como um todo.

Os novos tempos impõem transformações na base técnica, econômica, política, nas relaçóes sociais e, portanto, outros são os requerimentos à formação dos indivíduos, largamente apregoados pelos chamados "novos paradigmas educacionais".

As atuais transformações implicam uma massiva incorporação da ciência e da tecnologia como força produtiva direta. A base técnica da acumulação capitalista que até então exigia um investimento significativo em capital variável passa a exigir um maior investimento em capital constante. Com isso, a tecnologia microeletrônica desenvolve substancialmente a informática, dando uma nova característica à base técnico-material do sistema.

Nesse sentido, a sociedade do capital aparece como um mundo fantástico, luminoso, onde, até que enfim, o capital teria realizado seu sonho de ouro, qual seja, viver e reproduzir-se sem o trabalho. Não são poucos os que se habilitam a defender a tese do fim da "sociedade do trabalho", do fim do "valortrabalho".

A esse respeito, as teorias de Daniel Bell sobre a "sociedade pós-industrial", as de Habermas e as de Offe sobre o "capitalismo tardio" são bastante ilustrativas.

Bell tem por base um esquema conceitual no qual a sociedade é formada por três esferas distintas - estrutura social, política e cultural -, sendo cada uma 
delas regida por um princípio axial diferente. A partir desse esquema, que serve como um suposto antídoto à tentativa de analisar a sociedade como um todo mediante um único parâmetro, Bell afirma que o conceito de sociedade "pósindustrial”, cujo princípio axial é a tecnologia, refere-se apenas à estrutura social.

Nesse sentido, Bell, tendo a tecnologia como parâmetro de análise, elabora um esquema evolutivo em que o conceito de sociedade "pós-industrial" é contraposto aos de "pré-industrial" e de industrial. Enquanto para ele o setor "pósindustrial" é voltado principalmente para atividades de processamento, com base em telecomunicaçôes e computadores para veiculação de informação e conhecimento, o setor "pré-industrial" é mais voltado para atividades agrícolas e extrativas, e o industrial é definido como fabricante de bens manufaturados com base em tecnologia mecânica.

De acordo com Bell, na sociedade industrial, baseada em tecnologia mecânica, o capital e o trabalho são as principais características estruturais; as mercadorias industriais são produzidas em unidades distintas, cuja compra ou troca envolve a transferência da posse física e pode ser consumida ou usada como uma mercadoria qualquer; na manufatura de bens industriais pode-se estabelecer uma função de produção e determinar a combinação aproximada e o custo relativo de cada fator; por fim, a sociedade industrial caracteriza-se, segundo Bell, pela teoria do valor-trabalho, já que o capital é trabalho incorporado.

Para ele, a sociedade "pós-industrial" é baseada em tecnologia intelectual, em informação e em conhecimento que, diferentemente das mercadorias industriais, quando vendidos continuam com o produtor, por isso não se esvaem quando consumidos ou usados. Além do mais, o conhecimento é um produto social e a questão dos seus custos, preço ou valor, em muito difere da dos produtos industriais. Por fim, a sociedade "pós-industrial" é caracterizada por uma teoria do valor-conhecimento, já que é a codificação do conhecimento que se constitui na força diretiva da inovação.

Bell não sustenta que a sociedade pós-industrial substitui a industrial. Ele, porém, chama a atenção para as novas dimensôes que caracterizam a sociedade pós-industrial: a centralidade do conhecimento teórico, que se tornou a base das inovaçôes tecnológicas e a expansão do setor de serviços. De acordo com o esquema evolutivo proposto por Bell, enquanto na sociedade industrial o trabalho é um jogo contra a natureza, na sociedade pós-industrial, a natureza é excluída e o trabalho passa a ser um jogo entre pessoas - o burocrata e o cliente, o médico e o paciente, o professor e o aluno. Por trás dessa mudança na natureza do trabalho está outra de natureza conceitual, que é a substituição da teoria do valor-trabalho por uma teoria do "valor-conhecimento". No mesmo plano, caminha a perspectiva apologética de Toffler (1970; 1980; 1993), que postula o fim da "sociedade do trabalho" que teria então sido suplantada pela 
"sociedade do conhecimento", dando origem a um pretenso "cognitariado" em substituição ao proletariado.

Sob o aparente argumento de contrapor-se às chamadas teorias da sociedade industrial, Habermas e Offe desenvolveram a noção de "capitalismo tardio".

Segundo eles, essa noção baseia-se fundamentalmente nas mudanças estruturais vividas pelas sociedades capitalistas industrializadas desde o final do século XIX. Essas mudanças estruturais consistem, segundo Habermas, basicamente em duas tendências de desenvolvimento, que ele resume como: "um crescimento da intervenção estatal, com o objetivo de garantir a estabilidade do sistema, e uma crescente interdependência entre a pesquisa e a tecnologia, que converteu as ciências numa força produtiva dominante". (Habermas, 1970, p.68).

É com base nessas duas tendências que Habermas e Offe definem a sociedade atual como sendo de natureza diferente daquela do século XIX, sobre a qual Marx escreveu. Assim, a expressão "capitalismo tardio" é usada em contraposição a capitalismo liberal, justamente para diferenciar a sociedade industrial contemporânea do jovem capitalismo, que vigorou na Europa Ocidental até a metade do século XIX.

Naquela época, segundo os autores, a teoria do valor-trabalho formulada por Marx constituía-se num instrumento eficiente para destruir criticamente a aparência de liberdade representada pela instituição legal do contrato de trabalho livre. Ou seja, a teoria do valor-trabalho revelava as relações de dominação e exploração nas quais se baseava a instituição do trabalho assalariado.

Nesse sentido, para eles, últimos dos representantes da Escola de Frankfurt, o esquema analítico de Marx, baseado no valor-trabalho, que foi eficiente para explicar o funcionamento do capitalismo liberal, tornou-se insuficiente para explicar a realidade do atual "capitalismo tardio". A ação combinada das duas tendências apontadas por Habermas invalidaria as bases da teoria marxista do valor-trabalho.

Aqui, poderíamos aplicar o ensinamento marxiano presente no Dezoito Brumário, de Luiz Bonaparte:

Hegel observa em uma de suas obras que todos os fatos e personagens de grande importância do mundo ocorrem, por assim dizer, duas vezes. E esqueceu-se de acrescentar: a primeira vez como tragédia, a segunda como farsa... (Marx, 1982, p.329, grifo nosso).

Ou seja, aí está no que se transformou a Escola fundada por Adorno e Horkheimer.

O exposto acima permite ver, tendo por base as transformações estruturais vivenciadas pelas sociedades desenvolvidas, que tanto a teoria de Habermas e 
Offe sobre o "capitalismo tardio" quanto a de Daniel Bell sobre a "sociedade pós-industrial" questionam a atualidade da teoria marxiana do valor-trabalho.

A dissociação entre fato e pensamento, entre objetividade e subjetividade atinge, nos dias atuais, como podemos perceber pelas postulações teóricas acima pontuadas, magníficas proporções. Completamente alucinados pelo virtual, tais autores deixam de pensar o que o virtual representa e significa, proporcionando condiçōes para ser por ele (virtual) pensado. Expressão mais clara da organização do mundo pela cabeça. Ou seja, a materialidade perde seu princípio de ação e de realidade.

Busca-se substituir a materialidade pelo princípio voluntarista de uma "ação comunicativa", que se valida quando duas ou mais pessoas procuram expressamente chegar a um acordo voluntário de modo a poder cooperar entre si, mesmo que esse acordo não seja tão voluntário, se consideramos a possibilidade das proposições manipulativas. As soluções oferecidas por Habermas de uma "comunidade ideal de comunicação", de uma "situação ideal da fala" negam o conflito social e a sua resolução potencial. Ou seja, a materialidade é substituída pela transcendência de uma relação intersubjetiva em que o fundamental não é a atividade, mas a intenção subjetiva que os indivíduos conferem à sua ação. "Toda criança sabe que se uma nação parasse de trabalhar, não por um ano, mas por algumas semanas, pereceria". (Carta de Marx dirigida a Kugelmann, 11 de julho de 1868).

Ao dar essa resposta aos seus opositores que o acusavam de não ter provado o conceito de valor, Marx demonstra a importância da categoria trabalho. Ou seja, o homem deve a sua existência ao trabalho. O trabalho é pressuposto ontológico fundante de toda a sociabilidade, isto é, o fundamento das várias formas pelas quais nós organizamos a produção e a distribuição social da riqueza. Essa compreensão também aparece no Livro Um de $O$ capital: "Antes de tudo, o trabalho é um processo de que participam o homem e a natureza, processo em que o ser humano com sua própria ação, impulsiona, regula e controla seu intercâmbio material com a natureza". (Marx, 1984, p.202).

As atuais "metamorfoses" por que passa o sistema do capital produzem, assim, um largo debate acerca de suas várias consequiências. A par da radicalidade da crise atual do capital, movimentos no plano do pensamento o eternizam pela representação virtual da realidade. As teorias deixam de ser falsas ou verdadeiras e todos os discursos passam a construir a realidade, possuem o poder de instaurar a verdade. A razão e a ciência são postas sob suspeita. A simplificação e o relativismo, segundo os quais tudo é convencional, subjetivo e incapaz de refletir a objetividade, parecem ser a marca mais significativa do século XX. A tese de que, até que enfim, "chegamos ao fim da história", vem de um pensamento supostamente de direita, mas também de um pensamento supostamente de esquerda. 
Marca o início de um novo século, o que não difere do que parece ter sido o mal do século XX, uma posição gnosiológica de fundamentação subjetivista fortemente marcada por princípios agnósticos, que busca substituir a originalidade do pensamento marxiano, fundamentado pelos princípios da ontologia ou, como quer Netto (1994), pelos princípios de uma "Nova Ontologia".

É uma situação contraditória, por isso mesmo perfeitamente compreensível. São as condiçôes históricas e sociais da crise do mundo do capital que permitem e oferecem possibilidades de crítica a uma recuperação gnosiológica do pensamento marxiano, efetuada pelo discurso pretensamente marxista. Ao mesmo tempo, essas novas condiçōes históricas e sociais proporcionam a recuperação do pensamento marxiano de origem, necessária para a compreensão do momento atual.

A atual "reconversão produtiva" de farto investimento em capital constante obnubila o pensamento, tanto em sua face liberal quanto em sua face pretensamente "revolucionária". Este movimento de obscurecimento do pensamento praticamente expropria a subjetividade da objetividade, instaurando, então, um movimento que nomeia a realidade e, portanto, institui a realidade a seu bel-prazer. Disso parece resultar a seguinte proposição: resignemo-nos; predestinemo-nos; viveremos sob a égide eterna do mundo do capital. E, de preferência, sem o trabalho.

Esta é, sem dúvida, uma nova fase de acumulação, caracterizada pela crise, mas, também, pela versatilidade da produção e da utilização da força de trabalho. As transformações são de vulto, a tal ponto que estimulam um determinado modo de ver as novas tecnologias, como os sujeitos fundamentais dos processos sociais:

Na encruzilhada do capital e do trabalho, da matéria e da inteligência, as novas tecnologias mudaram, em duas ou três décadas, não só a nossa maneira de trabalhar, como toda a nossa maneira de viver. Elas se inscrevem num duplo movimento que caracteriza as sociedades desenvolvidas de hoje: a inserção cada vez maior de inteligência nos objetos, nas máquinas, nos processos de produção, de informação e de comunicação, de comercialização e, ao mesmo tempo, a mobilização crescente da inteligência nos processos econômicos e sociais. A "matéria cinzenta" é reconhecida como o principal recurso. (Caspar, apud Witkowski, 1995, p.81).

Apesar dessa visão equivocada que transforma a tecnologia em sujeito, é inegável que as novas tecnologias intelectuais de caráter interativo e fundamentadas na informática têm sido usadas para modificar as bases materiais da produção, da conservação e da transmissão dos conhecimentos. 
A noção de tempo real, ou seja, a organização/reorganização dos agenciamentos sociotécnicos, flexibilidade, fluxo tencionado, estoque zero, é o espírito da informática. Para Lévy, "Vivemos em uma cultura informáticomediática portadora de um tipo de temporalidade social baseada num 'tempo real' e em um 'conhecimento por simulação', não inventariado antes da chegada dos computadores." (1993, p.133).

Isso significa que essas modificaçôes tecnológicas põem e repõem as novas bases objetivas do modo de pensar e de produzir os conhecimentos. Nesse sentido, a relação sujeito/objeto é, hoje, mediatizada por diversos dispositivos informáticos, que dão novo conteúdo às atividades e às individualidades envolvidas nos processos de trabalho e de produção e reprodução dos conhecimentos.

São significativas as transformações que a informática, através de mecanismos multimídicos e de realidade virtual, pode provocar nos processos de formação humana. Os meios eletrônicos de massa e a tecnologia de informação podem trazer modificações substanciais aos processos formativos. Diferentemente da cultura escrita, na qual a reflexão se pauta pela utilização de categorias, na cultura informática o pensamento e a reflexão são mediados por procedimentos formais e por modelos computacionais. O novo modo de acesso à cultura dá-se através dos sistemas inteligentes, da realidade virtual, da multimídia, da TV interativa, do uso das várias "infovias" (redes computadorizadas de informação) e da Inteligência Artificial, que se situa no cruzamento da cognição, das Neurociências e da Informática, buscando compreender o pensamento e o comportamento humanos, a fim de reproduzi-los artificialmente.

Essas "metamorfoses" impõem como necessário o desenvolvimento de uma individualidade adaptada às mudanças, desenvolvem-se programas de formação e treinamento que enfatizam o desenvolvimento de novas percepçốes, novas representaçóes e novas atitudes, adequadas ao trabalho. Como projeto pedagógico, essa intervenção constitui-se em ações que visam o reordenamento da forma-de-ser dos trabalhadores, buscando alterar, portanto, suas condutas e suas práticas sociais, reordenando, então, sua individualidade.

Adequadas aos novos modelos de produção e de trabalho, que submetem os trabalhadores a uma validação permanente de sua adequação às atividades de trabalho, as atuais intervençôes pedagógicas do capital voltam-se para o desenvolvimento da capacidade do trabalhador em resolver problemas na produção e em transferir habilidades para o desempenho de tarefas reformuladas ou introduzidas no processo produtivo.

Essas atuais intervenções pedagógicas reforçam a idéia de uma formação da individualidade que seja adequada às necessidades de resolução de problemas $\mathrm{e}$ de transferências de habilidades. Estas voltam-se basicamente ao desenvolvi- 
mento de novas percepções, novas representações e novas atitudes, fundamentais para a formação da individualidade apta às novas transformaçôes tecnológicas.

Enfim, sabemos que não há uma relação mecânica entre base e superestrutura; porém, ao racionalizar a produção, proporcionamos condiçôes efetivas de racionalização do modo de viver. Às transformaçóes na base material da produção social acompanham mudanças no modo de viver, refletir e apreender a vida. Afinal, a base material em que se assenta a sociedade, bem como a tecnologia, é produto do trabalho humano e como tal sua "natureza" é social. Como todo produto humano, sua ação é contraditoriamente humana. Assim como o ser social realiza a história e é por ela realizado, afirmar que o homem realiza a base material e a tecnologia, assim como por elas é realizado, não tem nada de reificador nem tampouco as (a base material e a tecnologia) transforma em sujeito autônomo. As novas tecnologias intelectuais de caráter interativo possibilitam "conhecer" a realidade através de simulaçôes, o que leva a um relativo afastamento do empírico, promovendo mudanças no plano da racionalidade intrínseca aos processos de formação da individualidade humana. Essas mudanças recolocam as categorias de objetividade, subjetividade, individualidade e racionalidade no centro dos debates acerca das relaçôes entre o sujeito e o objeto do conhecimento. Portanto, traz novos desafios ao problema da formação humana na atualidade.

Há toda uma discussão na literatura acerca da melhor maneira de caracterizar os diversos processos de transformaçôes que ocorrem no mundo do capital desde os finais do século XIX. Tais transformaçōes caracterizariam um rompimento com os fundamentos da modernidade? A atual "pós-modernidade" caracterizaria uma nova forma de sociabilidade, o que determinaria uma nova ciência, portanto, uma nova forma de pensar o homem e o mundo, portanto uma nova individualidade humana?

Em nosso século, aparentemente, a valorização da autonomia da individualidade emerge como fundamento de um novo "paradigma". Uma pretensa nova relação entre sujeito e objeto desponta como parte de transformações objetivas. Lyotard (1990) a define como "condição pós-moderna" e afirma que esta se delineia desde o final do século XIX.

O "pós-moderno" seria uma condição dos discursos nas sociedades desenvolvidas. Para ele, seria um estado da cultura fundamentada por transformaçôes que vêm afetando as regras do jogo da ciência, da literatura e das artes.

Segundo esse pensamento "pós-moderno", as "metanarrativas" perderam seu poder explicativo do mundo. A ciência de hoje não mais pretenderia ser totalizante e muito menos afirmar qualquer tipo de verdade, ainda que provisória.

Para Lyotard, a fragmentação e a heterogeneidade das sociedades contemporâneas fazem com que suas práticas não possam mais ser legitimadas pelos 
"discursos universalistas". Ao valorizar as chamadas experiências particulares, de grupos e de indivíduos, as concepçóes "pós-modernas" rejeitam a idéia de totalidade. Seu eixo fundamental é constituído pela pluralidade, pela relatividade, pela particularidade, contrapondo-se à singularidade e à universalidade.

Essa mudança paradigmática dá-se em vários campos: nas ciências humanas e sociais, nas ciências biológicas e físicas, etc. Os discursos são articulados em torno de dicotomias como verdade/objetividade e falsidade/subjetividade.

Aqui, o objeto é aparentemente expropriado do sujeito, ou seja, o objeto não existe, a priori, objetivamente: ele é uma construção intelectiva dos sujeitos. Passa-se, então, a questionar a pretensa objetividade positivista e funcionalista e, como pretendem alguns, a objetividade marxista. Essa "nova visão paradigmática" entende que a idéia de determinação, não apenas no mundo social, mas também no mundo da natureza não é mais suficiente para explicar a vida.

Na biologia, a idéia de subjetividade também se incorporou ao modo como se passou a conceber a organização dos sistemas vivos. Considera-se que tudo o que é vivo é autocriativo e os organismos, como sistemas vivos, são criadores de si próprios. ${ }^{1}$

Essa concepção de que os fenômenos sociais e naturais são desprovidos de objetividade sobrevaloriza a emergência da aleatoriedade e do acaso e, com isso, a sobredeterminação das noçôes de subjetividade, individualidade e autonomia.

Essa "nova" forma em que se apresenta a irracionalidade traz consequiências significativas para o objeto da ciência, a partir do instante em que este passa a ser tratado como algo suscetível de ser modelado pela vontade ou pela razão.

Para Morin (1977, p.75), "o que é único real é a conjunção da ordem e da desordem". E, ainda, citando Serres (1974), afirma: "Sim, a desordem precede a ordem, e só a primeira é real".

Nesse sentido, esta concepção coloca-se diametralmente oposta à propositura cartesiana, super-relativiza os resultados do processo de conhecimento, ao supor que, se a ciência revela algum tipo de verdade, esta é subjetivamente construída.

Rejeita, assim, a idéia de que o conhecimento científico possa ser tratado como representação exata da realidade, como espelho da natureza. Deve, então, ser tratado como uma das diversas formas de representação da realidade. São discursos literários e artísticos sobre o mundo. Ou, como desejam os psicólogos e psicanalistas, são "olhares diferenciados sobre o mundo". Patética é a conclusão de que todos são verdadeiros.

1. Sobre isto ver Maturana e Varela ( 1973$)$. 
Fica claro, dessa forma, que essa concepção de mundo superestima o papel do sujeito, portanto, da individualidade como produtora da vida, pois considera que a idéia de indivíduo universal exclui as diferenças entre os sujeitos.

As consequiências dessa visão são patentes em toda a literatura que trata do assunto. Buscando reconceitualizar o vazio como um dos espaços de criação, a realidade "pós-moderna", como observa Guattari (1992), seria uma construção subjetiva e, portanto, se é construída, poderia ser desconstruída, interrogada, questionada.

É nesse sentido que Morin (1977, p. 82) propōe o paradigma da complexidade para desenvolver um novo método para o saber, de negação da visão universalista do mundo, afirmando, portanto, o relativismo.

Percebemos, portanto, que na concepção "pós-moderna", a noção de objetividade parece perturbar o sujeito.

Isso tem, no entanto, uma determinação objetiva. A partir do último quartel do século XX, as transformações socioeconômicas, políticas e culturais no capitalismo afetam significativamente os modos de vida e a organização social do mundo do capital.

O processo de aprofundamento da mundialização do capital, o desenvolvimento de novas tecnologias e de novas formas de organização e de gerenciamento dos processos de trabalho implicam um processo de fragmentação social nunca antes visto; são expressão disto o número de guetos pauperizados, a favelização das cidades e a exacerbação da exclusão social.

Torna-se inviável a comunicação e a coexistência de realidades socioculturais diferentes no capitalismo de hoje. O aumento da desigualdade social, sobretudo nas duas últimas décadas do século passado, revela os efeitos excludentes do processo de desenvolvimento do capitalismo.

São entraves concretos à realização das promessas universalistas da modernidade. No bojo desse mesmo processo, surgem as concepçôes que reivindicam a particularidade e a autonomização da subjetividade em relação à objetividade.

Como observa Guattari (1992), as mesmas transformaçôes tecnológicas que levaram a uma tendência de "homogeneização universalizante e reducionista da subjetividade também levaram a uma tendência heterogenética e de singularização dos seus componentes".

O que está em questão, nessa forma de ver o mundo, é a negação da possibilidade cognoscente das chamadas "metanarrativas" em favor de uma suposta pluralidade e relatividade da possibilidade cognoscente do mundo.

Ou seja, é a luta de diferentes individualidades singularizantes por se fazerem reconhecidas no mundo. Um dos efeitos mais expressivos dessa forma de 
ver o mundo residiria na impossibilidade de uma ação social fundamentada em um projeto unitário. Nesse sentido, muitos passam a afirmar que "não é mais possível se livrar do mundo do capital”. O pragmatismo parece ser a única filosofia possível de ação.

Para Mészáros (1996, p. 63),

as teorias da "modernidade" e da "pós-modernidade" preenchem as exigências ideológicas das circunstâncias de conflito mais agudo. Ambas evitam fazer suas proposiçóes teóricas fundamentais a partir da situação histórica dada. As referências aos processos sociais existentes parecem mais observaçóes ilustrativas ocasionais do que parte essencial da própria teoria. Não há conexão inerente entre o discurso teórico geral e o "mundo da atividade concreta" da ordem sócio-histórica dada.

Seguindo, então, esse raciocínio, essas concepções não seriam suficientes "até mesmo em seus próprios termos de referência".

"Em sua absoluta negatividade, elas parasitam as formas rejeitadas de discurso emancipatório". Não podem abandonar totalmente as preocupaçóes emancipatórias. São incapazes de "indicar, ao mesmo tempo, com base na dinâmica histórica real, algumas forças possíveis da emancipação individual e social”.

Esta lacuna - que decorre da rejeição categórica do trabalho como agente de emancipação - traz consigo consequiências metodológicas profundas, compartilhadas tanto pelos ideólogos da "modernidade" quanto pelos da "pós-modernidade". (Mészáros, 1996, p. 67).

É desse modo que a concepção de Lyotard se emaranha em uma aporia fundamental. Como nos diz Mészáros: "o único conteúdo real que ele pode proporcionar à sua 'pequena narrativa' idealizada é a discussão das 'metaprescriçóes' a serem adotadas pelos vários grupos."

Ou seja, para estabelecer as interconexões e mediações globais necessárias, "seria levado a reformular outro 'metadiscurso' ou 'grande narrativa'".

Por outro lado, entretanto, pelo modo como se propóe a solucionar seu dilema, sua teoria geral não termina com uma estrutura exequível, isenta de características metadiscursivas, mas, ao contrário, com um metadiscurso de segunda ordem que se esgota na discussão de regras de aplicabilidade estruturalmente dúbia. (Mészáros, 1996, p. 68). 
A ontologia social marxiana, ao negar a possibilidade de compreensão da essência humana de forma abstrata, apontando que esta só pode ser apreendida e compreendida em sua citerioridade, ou seja, em sua condição real de existência, pode representar a saída desse emaranhado de aporias identificadas e presentes nas teorias sociais até aqui apresentadas e discutidas.

Toda e qualquer sociedade assenta-se em uma concepção de formação humana que the é própria. As sociedades existem através da atividade dos indivíduos, que buscam realizar seus próprios fins. São questões fundamentais para qualquer sociedade a produção e a reprodução de indivíduos que não negam as potencialidades do modo de produção predominante. Nesse sentido, os processos de formação humana são responsáveis, definem e reproduzem a estrutura de valores correspondentes à base objetiva na qual se assentam.

A sociabilidade do mundo do capital não se reproduz automaticamente. A sua reprodução só se dá mediante a adoção, pelos indivíduos, das perspectivas gerais da sociedade capitalista como o limite de suas aspiraçóes. Nesse sentido, a potencialidade de uma transcendência positiva dos processos de estranhamentos característicos do trabalho concreto no seio do capitalismo exige uma revolução radical nas concepçôes de formação humana. Mesmo que esta não seja a única necessidade a ser conquistada, tendo em vista a completude da transcendência positiva para além do capitalismo.

Pois, como diz Marx nos Manuscritos de 1844, o homem possui "um sentido restrito", vive cheio de preocupaçôes e não tem ouvidos para a música; o comerciante de minerais vê apenas o valor mercantil, mas não vê a beleza e a natureza singular das pedras: falta-lhe o "sentido mineralógico". Na sociabilidade posta pelo mundo do capital, o homem é incapaz de ver o que o olho nunca viu e de ouvir o que o ouvido nunca ouviu.

Esta incapacidade humana é determinada historicamente. Ou seja, são as condiçôes objetivas do capitalismo que refreiam os sentidos físicos e mentais, proporcionando o estranhamento de todos os sentidos humanos. Estes são subordinados ao sentido do ter.

Acerca do futuro da sociedade tecnologicamente avançada não faltam cenários e especulaçóes. A entronização irrefletida das novas tecnologias na linguagem comum como sujeito da história é de um modo geral inquietante.

As inovações tecnológicas, organizacionais e gerenciais são fundamentais à atual reestruturação dos processos de produçãa e reprodução do capitalismo. Porém, como diz Machado (1995), "elas, entretanto, por si mesmas, não são capazes de produzir mais valor, apenas potenciam quem tem essa prerrogativa, 
o trabalho humano".

Nesse sentido, para a educação entendida como formação integral do Ser Social deve permanecer central uma compreensão que não inverta a relação sujeito/objeto, que não faça da técnica e da tecnologia um pólo oposto, autônomo, mas que as mantenha sob responsabilidade e controle do homem.

Apesar do relativo aumento do tempo livre, da expansão das possibilidades de consumo e de comunicação, a posição social do indivíduo, sua chance de participação na configuração da política e da cultura permanece ainda essencialmente determinada por sua posição no sistema produtivo.

Se, por um lado, o trabalhador, que hoje se encontra em empregos qualificados, é privilegiado, por outro, os excluídos do sistema vivem uma situação de grande desigualdade.

$\mathrm{O}$ fenômeno mais evidente desse processo de desenvolvimento técnico e tecnológico é a perda da solidariedade, cujas consequiências serão difíceis de deter através de apelos morais e de sacrifícios de solidariedade individuais e coletivos.

Quanto mais se expandem, na vida como um todo, tendências de individualismo, isolamento e divisão, mais importante se torna desenvolver atitudes de integração social e de solidariedade. É nesse sentido que se torna necessário reafirmar a possibilidade, prática e teórica, do resgate do homem em sua integridade, ou seja, buscar a integração entre objetividade e subjetividade como uma questão ontológica fundamental, tendo em vista os fundamentos de uma concepção superior de indivíduo e de subjetividade humana.

É evidente que os sistemas informáticos, ao incidirem diretamente sobre todas as formas de produção de imagens, enunciados, idéias, pensamentos, percepçôes, representaçôes, afetos e atitudes, estão trazendo novas consequiências para as formas de consciência da individualidade humana. Consequiências que não podem ser discutidas meramente em termos de positividade e negatividade.

Mais que nunca, a centralidade ontológica do trabalho afirma-se como dimensão fundamental da formação humana. O conhecimento, a informação, são produtos do trabalho e não o inverso.

\section{Referências bibliográficas}

BELL, Daniel. Oadvento da sociedade pós-industrial. São Paulo: Cultrix, 1977.

CASPAR, Pierre. O futuro dos investimentos imateriais. In: WITKOWSKI, Nicolas. Ciência e tecnologia hoje. São Paulo: Ensaio, 1995. 
CHESNAIS, Fraçois. A mundialização do capital. São Paulo: Xamã, 1996.

FRIGOTTO, Gaudêncio. A produtividade da escola improdutiva: um (re) exame das relaçóes entre educação e estrutura econômica social e capitalista. São Paulo: Cortez, 1989.

GUATTARI, F. Caosmose; um novo paradigma estético. Rio de Janeiro: Editora 34, 1992.

HABERMAS, J. A nova intransparência. Novos Estudos CEBRAP, São Paulo, n.18, set. 1987.

HABERMAS, J. Conhecimento e interesse. Rio de Janciro: Zahar, 1982.

HABERMAS, J. O discurso filosófico da modemidade. Lisboa: Dom Quixote, 1990.

HABERMAS, J. Trabalho e Interação. In: HABERMAS, J. Ciência e técnica como ideologia. Lisboa: Ediçôes 70, 1970.

LÉVY, P. As novas técnicas de administração do saber. In: WITKOWSKI, Nicolas. Ciência e tecnologia hoje. São Paulo: Ensaio, 1994. p. 39-40.

LÉVY, P. As tecnologias da inteligência; o futuro do pensamento na era da informática. Rio de Janciro: Ed. 34, 1993.

LYOTARD, Jean-François. Opós-modemo. [s.1]: José Olympio, 1990. 123p.

MACHADO, Lucília Regina de Souza. Formação geral e especializada; fim da dualidade com as transformaçóes do capitalismo? Revista Brasileira de Educação, n. 0, p. 83-93, set./dez., 1995.

MARX, K. O 18 Brumário e cartas a Kugelmann. Rio de Janeiro: Paz e Terra, 2002.

MARX, K. O capital: crítica da economia política. Livro 1: o processo de produção do capital. São Paulo: Difel, 1984

MARX, Karl; ELGELS, F. Obras escolhidas em três tomos. Moscovo: Editorial Avante- Edições Progresso Lisboa, 1982.

MATURANA, Humberto. Emoçôes e linguagem na educação e na politica. Belo Horizonte: Editora da UFMG, 1999.

MATURANA, H. R.; VARELA, F. J. De máquinas y seres vivos. Santiago: Universitária, 1973.

MÉSZÁROS, István. Beyond capital: towards a theory of transition. Monthly Review. London, Merlin Préss. 1995. [Edição brasileira: Para além do capital. São Paulo: Boitempo, 2004.]

MÉSZÁROS, István. A ordem do capital no metabolismo social da reprodução. Ad Hominem - Tomo I-Marxismo. São Paulo, 1999.

MÉSZÁROS, István. Filosofia, ideologia e ciência social. São Paulo: Ed. Ensaio, 1993.

MÉSZÁROS, István. Opoder da ideologia. São Paulo: Ensaio, 1996.

MÉSZÁROS, István. Produção destrutiva e estado capitalista. São Paulo: Ensaio, 1989. 105p.

MORIN, Edgar. Terra pátria. [s.1.]: Editora Sulina, 1995.

MORIN, Edgar. A noção de sujeito. In: SCHNITMAN, Dora Fried (Org.). Novos paradigmas, 
cultura esubjetividade. Porto Alegre: Artes Médicas, 1996. p. 45-59.

MORIN, Edgar. O Método; a natureza da natureza. [s.1]:Publicaçôes Europa-América, 1977. OFFE, Claus. Capitalismo desorganizado. São Paulo: Editora Brasiliense, , 1994.

PAULO NETTO, José. Razão, ontologia c práxis, Revista Serviço Sociale Sociedade, n. 44, abr. 1994.

TOFFLER, Alvin. A terceira onda. Rio de Janeiro : Record, 1980.491p.

TOFFLER, Alvin. Guerra e anti-guerra; sobrevivência na aurora do terceiro milênio. Rio de Janeiro: Record, 1994. 349 p.

TOFFLER, Alvin. Powershift; as mudanças do poder. Rio de janeiro: Record, 1993.613 p.

WITKOWSKI, Nicolas. Ciência e tecnologia hoje. São Paulo: Ensaio, 1994. 449 p.

Recebido em 14 de agosto de 2007 e aprovado em 28 de março de 2008. 